\title{
APPLICATION OF C-FRP SHEETS FOR STRUCTURAL REPAIRING OF RC BEAM-COLUMN CONNECTIONS DAMAGED UNDER CYCLIC LOADING - EXPERIMENTAL STUDY
}

\author{
Emmanouil Golias $^{1}$, Stavroula Katsimente ${ }^{2}$, Eirini Ziavra ${ }^{2}$, Konstantinos Kirtsonis ${ }^{2}$, \\ Constantin E. Chalioris ${ }^{3}$, and Chris C. Karayannis ${ }^{4}$ \\ ${ }^{1}$ Dr. Civil Engineer \\ Democritus University of Thrace, Department of Civil Engineering, \\ Division of Structural Engineering, Xanthi 67100, GREECE \\ e-mail: egkolias@civil.duth.gr \\ ${ }^{2}$ Graduate students \\ Democritus University of Thrace, Department of Civil Engineering, \\ Division of Structural Engineering, Xanthi 67100, GREECE \\ e-mails: 1kats12@yahoo.gr, eiriniziavra1@gmail.com,kyrkost@outlook.com \\ ${ }^{3}$ Associate Professor \\ Democritus University of Thrace, Department of Civil Engineering, \\ Division of Structural Engineering, Xanthi 67100, GREECE \\ e-mail: chaliori@civil.duth.gr \\ ${ }^{4}$ Professor \\ Democritus University of Thrace, Department of Civil Engineering, \\ Division of Structural Engineering, Xanthi 67100, GREECE \\ e-mail: karayan@civil.duth.gr
}

\begin{abstract}
The effectiveness of externally applied Carbon Fiber-Reinforced-Polymer (C-FRP) sheets for the retrofitting of damaged Reinforced Concrete $(R C)$ beam-column connections is experimentally investigated. Two real-scale exterior $R C$ beam-column connection specimens are tested under reverse cyclic deformation. The damaged specimens have been repaired using C-FRP sheets superficial placed as surface reinforcement after the sealing of the developed cracks with high strength resin paste. The retrofitted joints re-tested under the same reverse cyclic deformation loading. The retrofitted specimens in comparison with the original ones exhibited more or less similar load capacity and stiffness level with respect to the original ones.
\end{abstract}

Keywords: Reinforced Concrete, Beam-column connections, C-FRP sheets, Cyclic tests, Hysteretic response. 


\section{INTRODUCTION}

Structural repair and upgrading of Reinforced Concrete (RC) beam-column joints in damaged RC frame structures after seismic excitations is a common problem in seismic prone regions. Researchers have published during the last decades valuable research on the postearthquake rehabilitation procedures of damaged beam column joints [1], [2]. Many efforts have been done so far for the introduction and the establishment of techniques that are based on the promising material of Fiber-Reinforced Plastics (FRP) sheets [3], [4], [5], [6], [7].

A well-known efficient rehabilitation technique of $\mathrm{RC}$ beam-column joints damaged during earthquake excitations is the application of FRP sheets in combination with resin injections. It includes thin resin infusion under pressure in the cracks of the damaged area prior to the application of FRP sheets on the damaged body. The efficacy of this combined procedure of resin injection and FRP sheets for the strengthening of damaged beam-column connections has also been the subject of the experimental project by Karayannis and Sirkelis (2008) [4] and Tsonos et al (2017) [2]. Nevertheless, the increasing interest in the use of FRP sheets, due to the immediate and easy-to-apply nature of the required intervention, was the main motive behind the simplification of the rehabilitation technique by omitting the use of resin injections prior to the application of the FRP sheets [8]. Addressing the issue of the efficiency of any strengthening technique it is important to remember that the seismic behavior of reinforced concrete connections involves the interaction of complex phenomena such as bond, shear, confinement, fatigue which have not been yet well understood [9], [10], [11]. Since many unanswered questions remain about the traditionally reinforced connections it is justifiable to consent for a certain measure of uncertainty for the mechanics of joints with superficially applied C-FRP sheets as external strengthening reinforcement [12], [13]. Despite all the uncertainties and based on the justified thought that a structural member can adequately be re-designed and strengthened to resist seismic loading even without full knowledge of all the involving interacting phenomena, this easy-to-apply technique is experimentally investigated.

This simplified technique is usually adopted in areas after damaging earthquakes due to the fast and easy-to-apply required procedure. This treatment of the damaged beam column joints has been mainly based on the generally accepted concept that in all reported cases the application of FRP sheets has been proved rather successful. In this direction, the experimental study presented herein investigates the efficacy of the rehabilitation of damaged beam-column connections using FRP sheets after a meticulous but superficial repair of the cavities and cracks of the damaged area using resin paste. The investigation presents experimental results of 4 realscale beam column specimens; two original specimens and two retrofitted ones. The original two joint specimens first were subjected to cyclic loading and then repaired with C-FRP sheets. The reteofiited specimens were re-subjected to the same cyclic loading and the observed results are used for the evaluation of the efficiency of the applied repair technique.

\section{CHARACTERISTICS OF THE SPECIMENS}

Cross-sections, dimensions, materials and reinforcement arrangements of the specimens were chosen in the way that the first specimen (BJB-S1) represents common RC buildings designed according to earlier codes without the proper shear reinforcement in the joint body (only one stirrup in the joint area) whereas the second specimen (BJB-BX) represents cases with Xtype reinforcement in the joint without stirrups.

The maximum joint shear that can be developed in the joint body by the steel bars of the beam is $0.32 \mathrm{MN}$ and consequently shear stress equal to $3.67 \mathrm{MPa}$. The ratio $\Sigma \mathrm{M}_{\mathrm{c}} / \Sigma \mathrm{M}_{\mathrm{b}}$ is almost 1.40 (a little higher) and therefore cracks are expected to be developed both in the joint body and the part of the beam near the joint (ACI 318). 


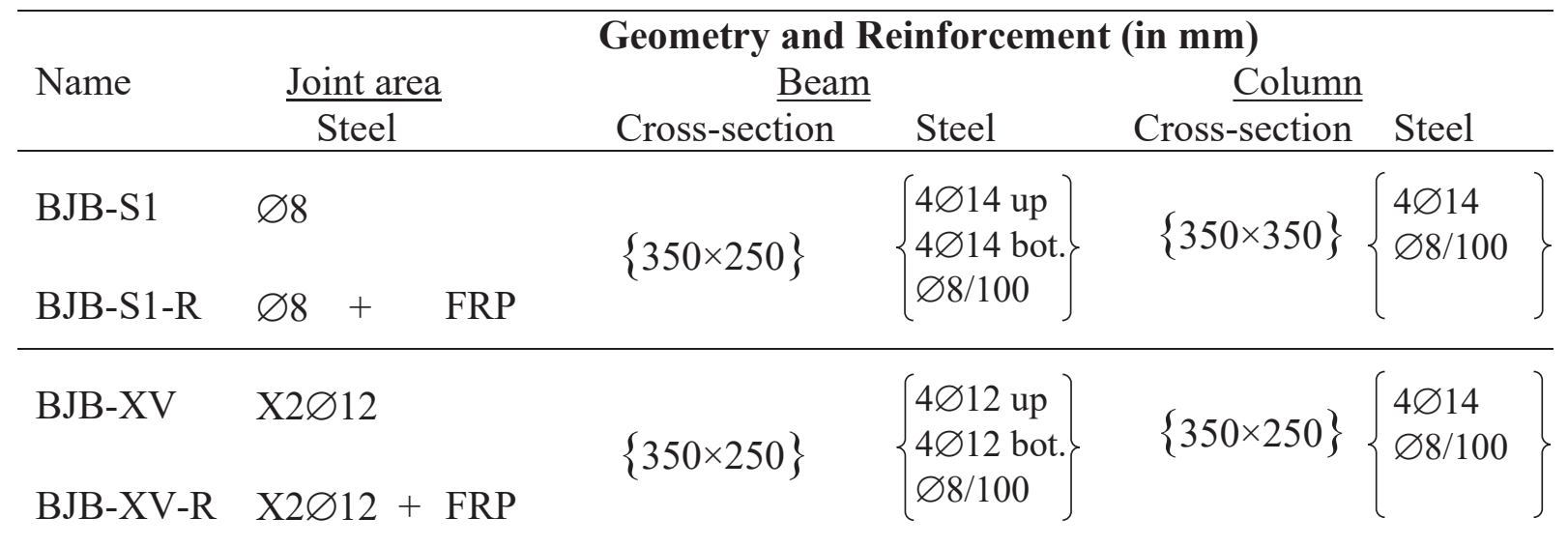

Table 1: Geometrical and reinforcement characteristics of the tested exterior beam-column joint specimens.

The total length and cross-section of the column are $3.0 \mathrm{~m}$ and $350 / 250 \mathrm{~cm}$, respectively, whereas the free length and the cross-section of the beam are $1.875 \mathrm{~m}$ and $350 / 250 \mathrm{~cm}$, respectively. The list of the tested beam column specimens, their names, the geometrical characteristics and the reinforcement arrangements are presented in Table 1.

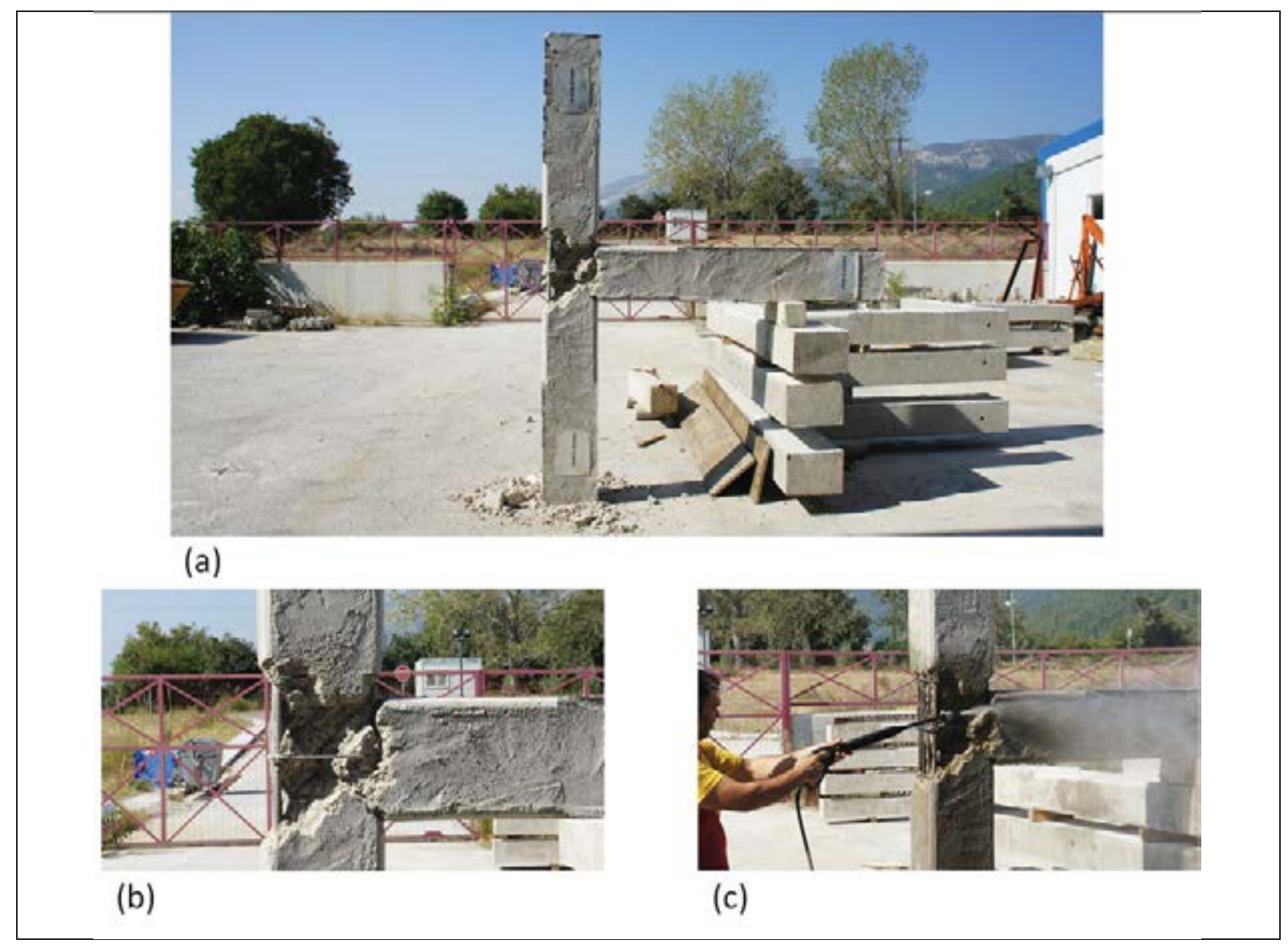

Figure 1: Damage of the joint $(a, b)$. Cleaning $(c)$ of the damage area and removal of loose material.

\subsection{Application of the C-FRP sheets}

The FRP sheets are applied to the body of the damaged joints after a superficial repair of the damage. First, cleaning and removal of the loose concrete material takes place (Figure 1). Right 
after, meticulous filling of the cavities and the developed cracks is performed with high strength resin paste (Figure 2). Prior to the application of the C-FRP sheets abrasion of the surfaces is absolutely necessary (Figure 2c).

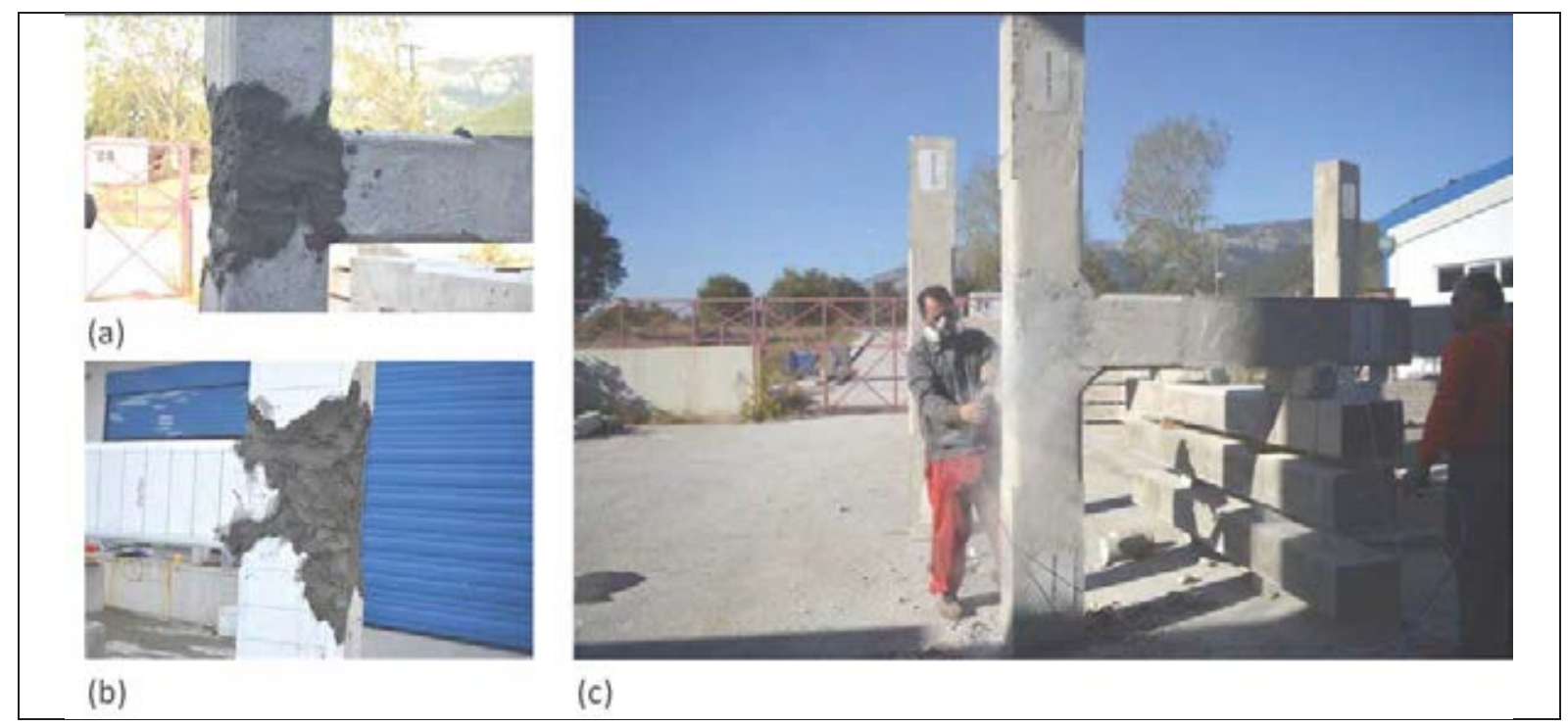

Figure 2: Filling of the developed cavities and cracks with high strength resin paste $(a, b)$ and meticulous abrasion of the surfaces (c) prior to the C-FRP application.

The positions of the applied C-FRP sheets are schematically shown in Figure $3 \mathrm{a}$ and application works in Figures $3 \mathrm{~b}$ and c. As presented in Figure $3 \mathrm{a}$ the C-FRP sheets are placed round the joint body and round the critical parts of the upper and down column and the beam.

\subsection{Materials}

The concrete's cylinder compressive strength was 34MPa whereas the yield tensile strength of the longitudinal steel bars and the stirrups was 550MPa. The type of the fiber-reinforced plastics sheets was Carbon FRP sheets. The characteristics of the used C-FRP sheets as given by the manufacturer were: Thickness of the sheets $0.168 \mathrm{~mm}$, tensile strength $4300 \mathrm{MPa}$ and tensile modulus of elasticity $240 \mathrm{GPa}$.

\subsection{Loading procedure and test setup}

The loading procedure of the specimens includes full reverse cyclic deformations that are applied near the free end of the beam. The examined beam column subassemblages are subjected to seven loading steps and each step comprised three full cycles as shown in Figure 4. The used loading program permits the evaluation of the structural performance parameters of the specimens.

The experimental setup and the instrumentation are shown in Figure 5. Each beam-column joint specimen is placed after $90^{\circ}$ counter clockwise rotation in the way that the column is in the horizontal direction whereas the beam is in the vertical direction. The specimen is supported by rotational devices that allow rotation to simulate the inflection points of the real columns in the middle of their heights.

Compressive axial load equal to $150 \mathrm{kN}$ is applied to the horizontally placed column element throughout the testing procedure. This loading is almost equal to $5 \%$ of the nominal strength of the concrete section of the column $\left(0.05 \mathrm{~A}_{\mathrm{c}} \mathrm{f}_{\mathrm{c}}\right)$. 


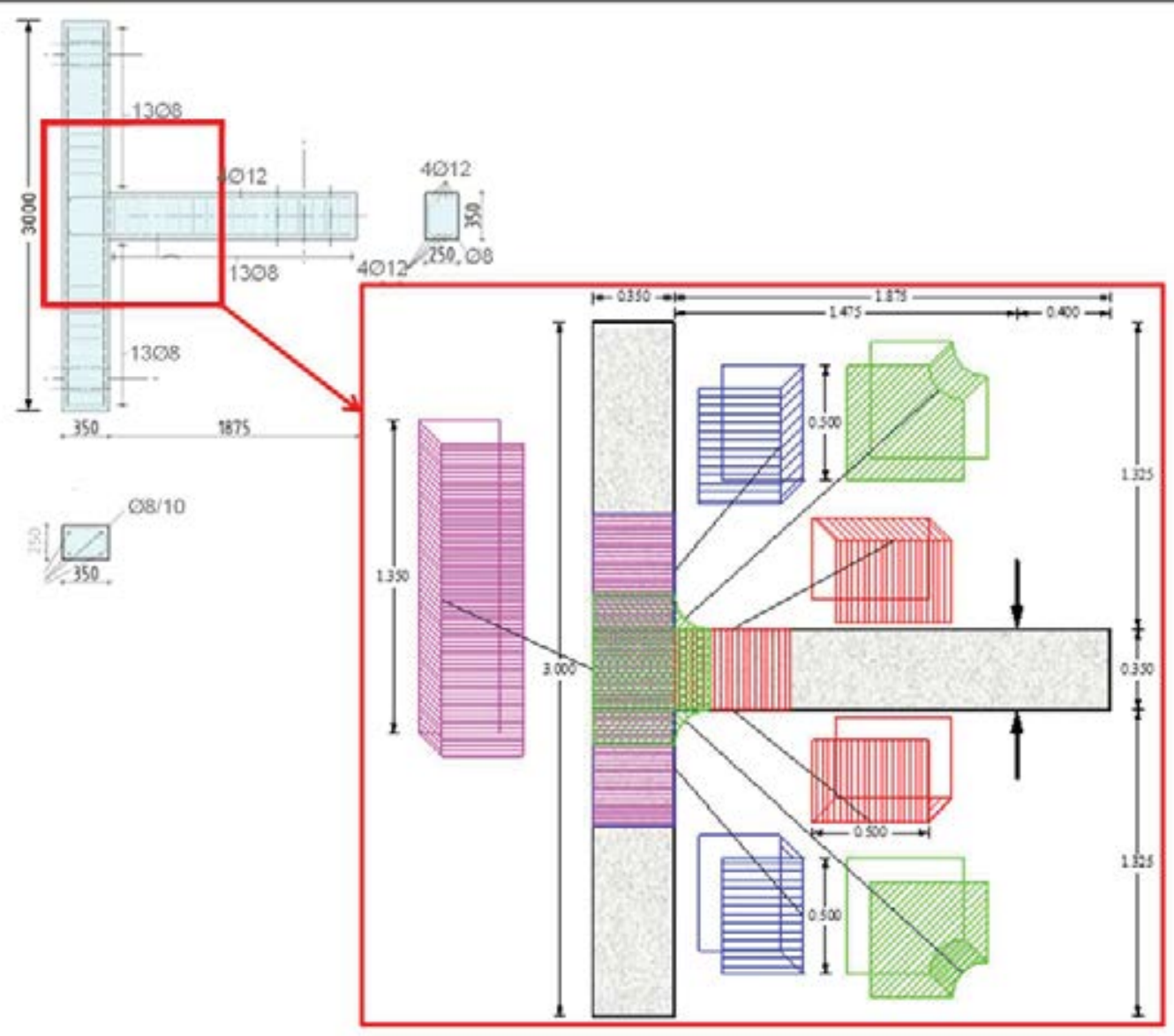

(a)

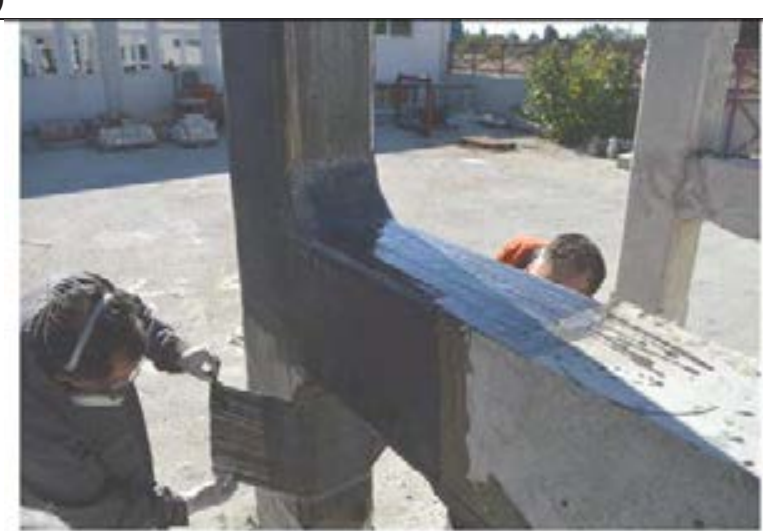

(b)

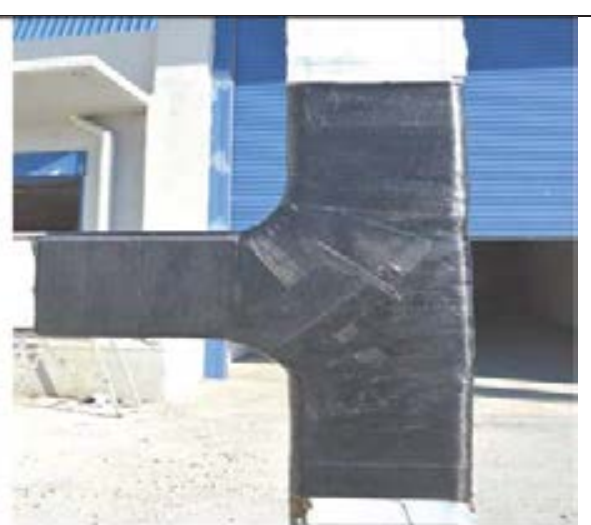

(c)

Figure 3: Schematic application of the C-FRP sheets (a) and application works of the C-FRP sheets (b, c).

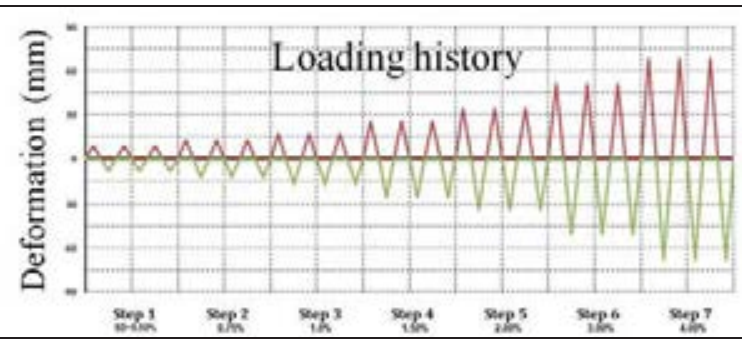

Figure 4: Loading procedure 


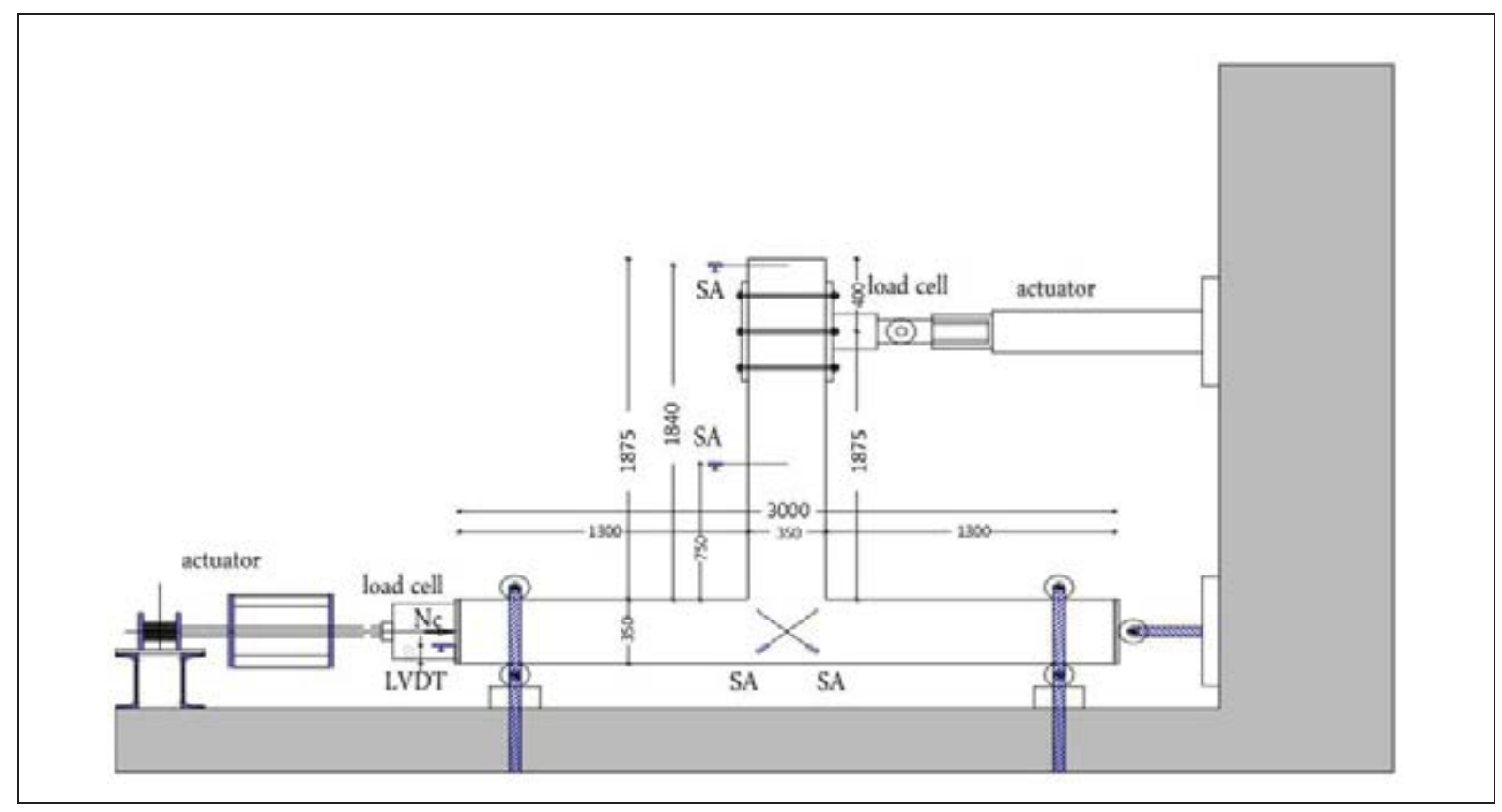

Figure 5: Test setup.

\section{TEST RESULTS AND DISCUSSION}

For the evaluation of the efficiency of the studied retrofitting procedure the overall performance of each original beam column joint is examined and compared to the performance of the corresponding retrofitted one in terms of hysteretic responses and energy dissipation curves.

\subsection{Hysteretic responses - Load carrying capacity}

The hysteretic responses of the original joint BJB-S1 and the corresponding retrofitted one BJB-S1-R are presented in Figures $6 \mathrm{a}$ and $6 \mathrm{~b}$, respectively. Further, the cracking patterns of these specimens at the end of the loading sequence are presented in Figures $6 \mathrm{c}$ and $6 \mathrm{~d}$, respectively. For comparisons purposes the envelope curves for the three full cycles per loading step, of these two tested specimens, BJB-S1 and BJB-S1-R, are shown in Figures 7a and 7b, respectively. The comparison of the hysteretic curves and the envelope curves obtained from the original joint and the corresponding ones obtained from the testing of retrofitted joint indicates that the application of C-FRP sheets restored the capacity values of the damaged joint in respect to those of the original specimen, to a great degree.

The hysteretic responses of the original joint BJB-XV and the corresponding retrofitted one BJB-XV-R are presented in Figures $8 \mathrm{a}$ and 8b, respectively. Further, the cracking patterns of these specimens at the end of the loading sequence are presented in Figures $8 \mathrm{c}$ and $8 \mathrm{~d}$, respectively. For comparisons purposes the envelope curves for the three full cycles per loading step, of these two tested specimens, BJB-XV and BJB-XV-R, are shown in Figures 9a and 9b, respectively. The comparison of the hysteretic curves and the envelope curves obtained from the original joint and the corresponding ones obtained from the testing of retrofitted joint indicates that the application of C-FRP sheets restored the capacity values of the damaged joint in respect to those of the original specimen, to a great degree.

Nevertheless, from the observations it is concluded that there are some reservations for the efficiency of the technique in the restoration of the load bearing capacity in cases of high levels of loading or high levels of initial damage. 

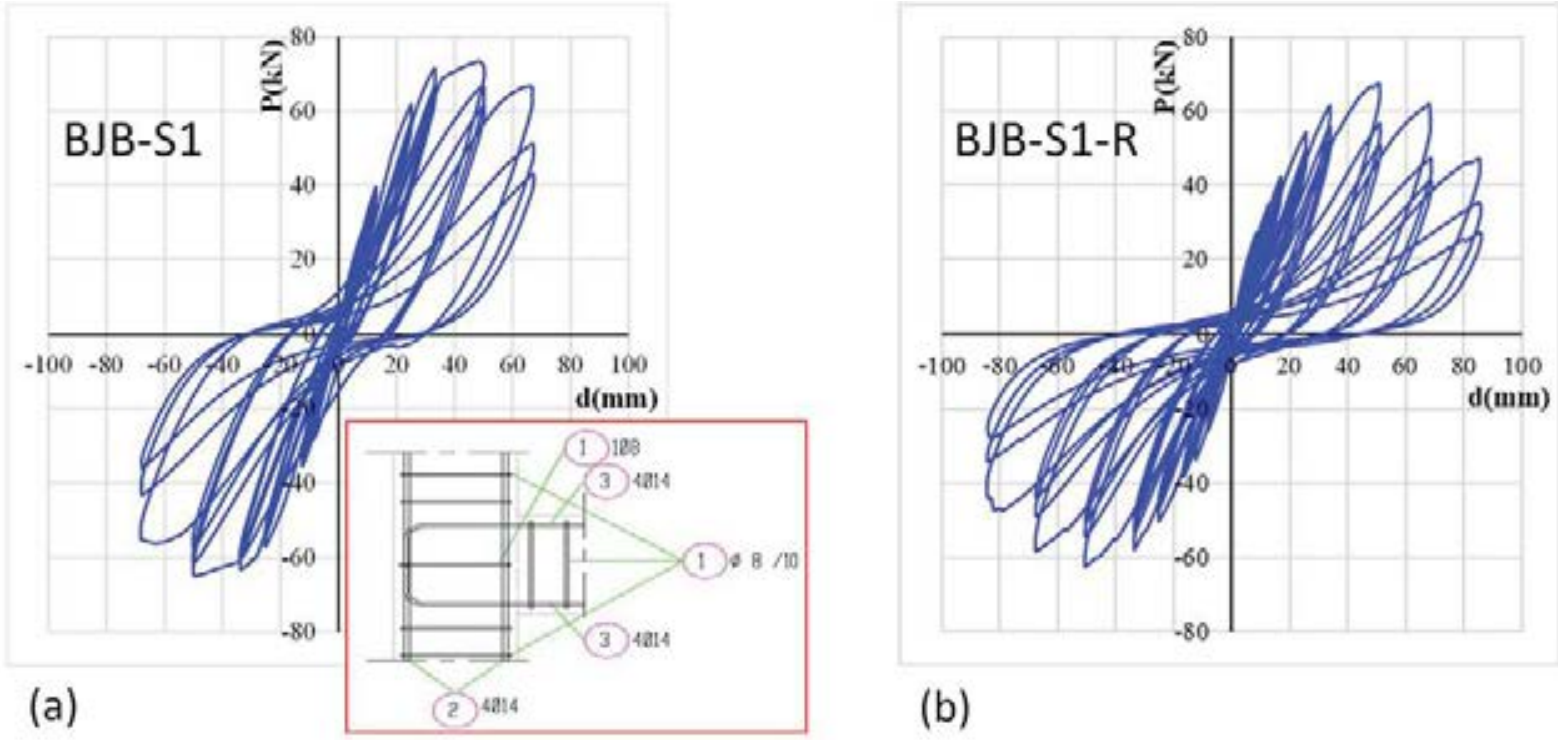

(b)

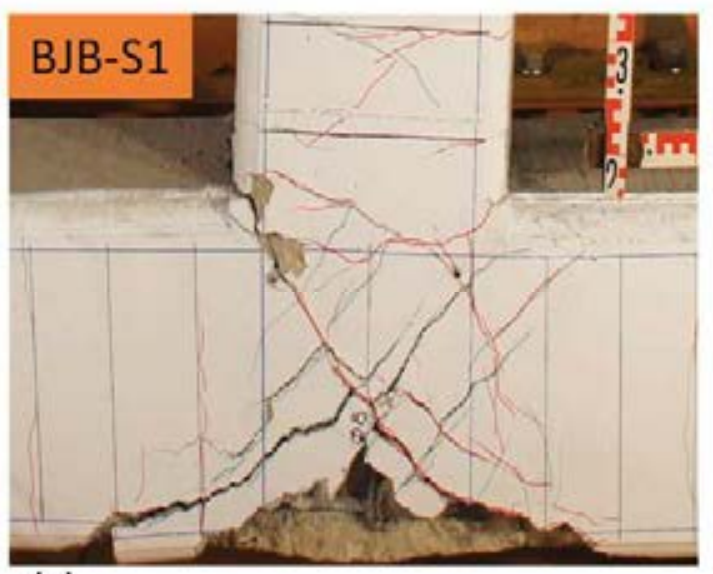

(c)

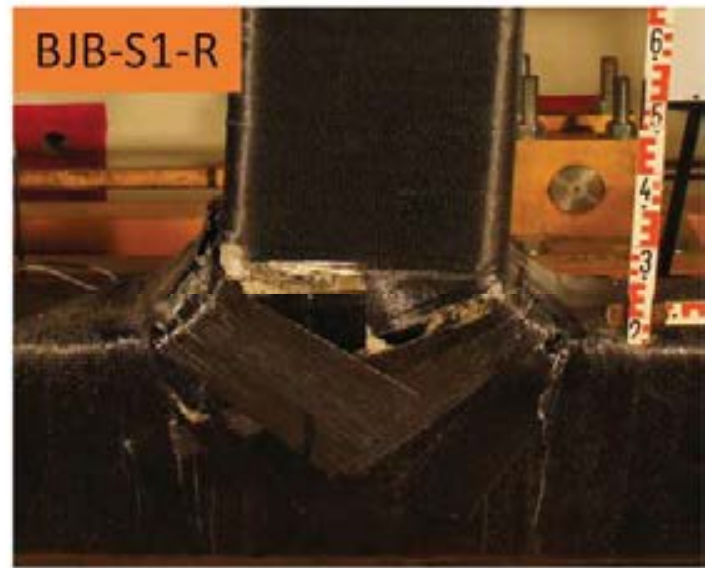

(d)

Figure 6: Hysteretic response (a) of the specimen BJB-S1 and hysteretic response (b) of the corresponding repaired specimen BJB-S1-R and cracking pattern at the end of loading of the same specimens (c, d).

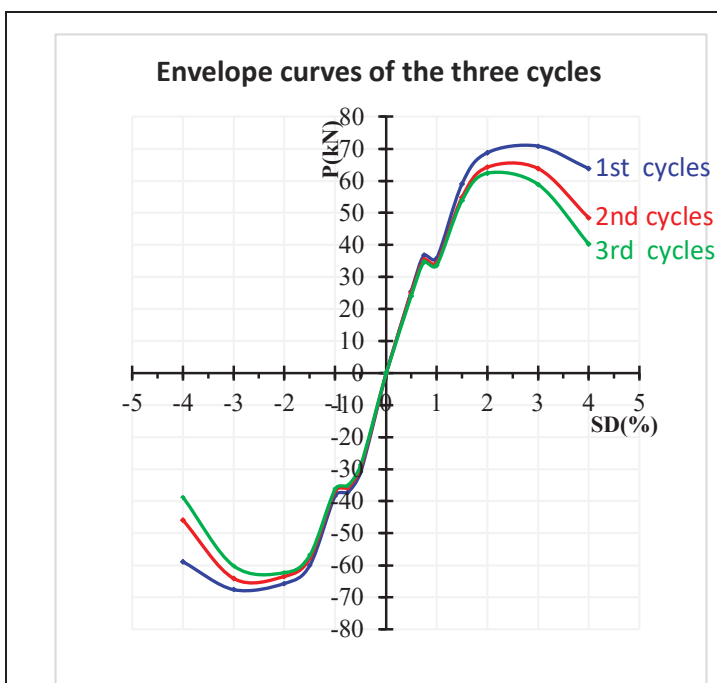

(a)

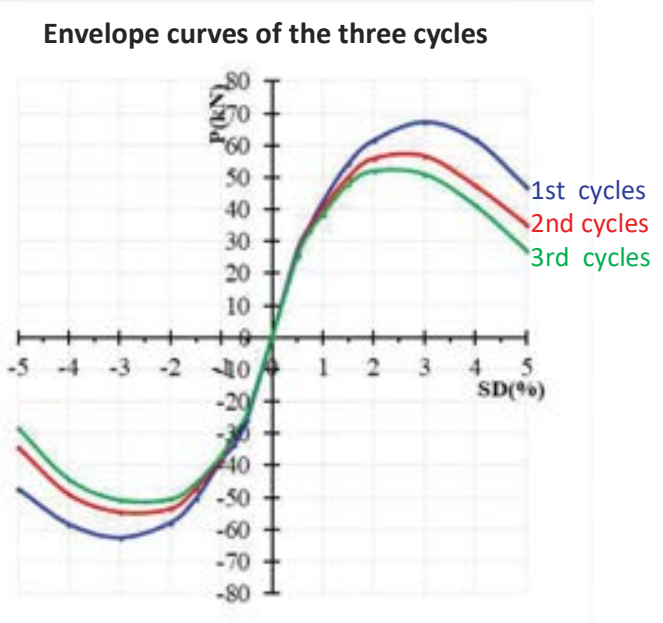

(b)

Figure 7: Envelop curves of the hysteretic responses (a) of the specimen BJB-S1 and (b) of the corresponding repaired specimen BJB-S1-R. 

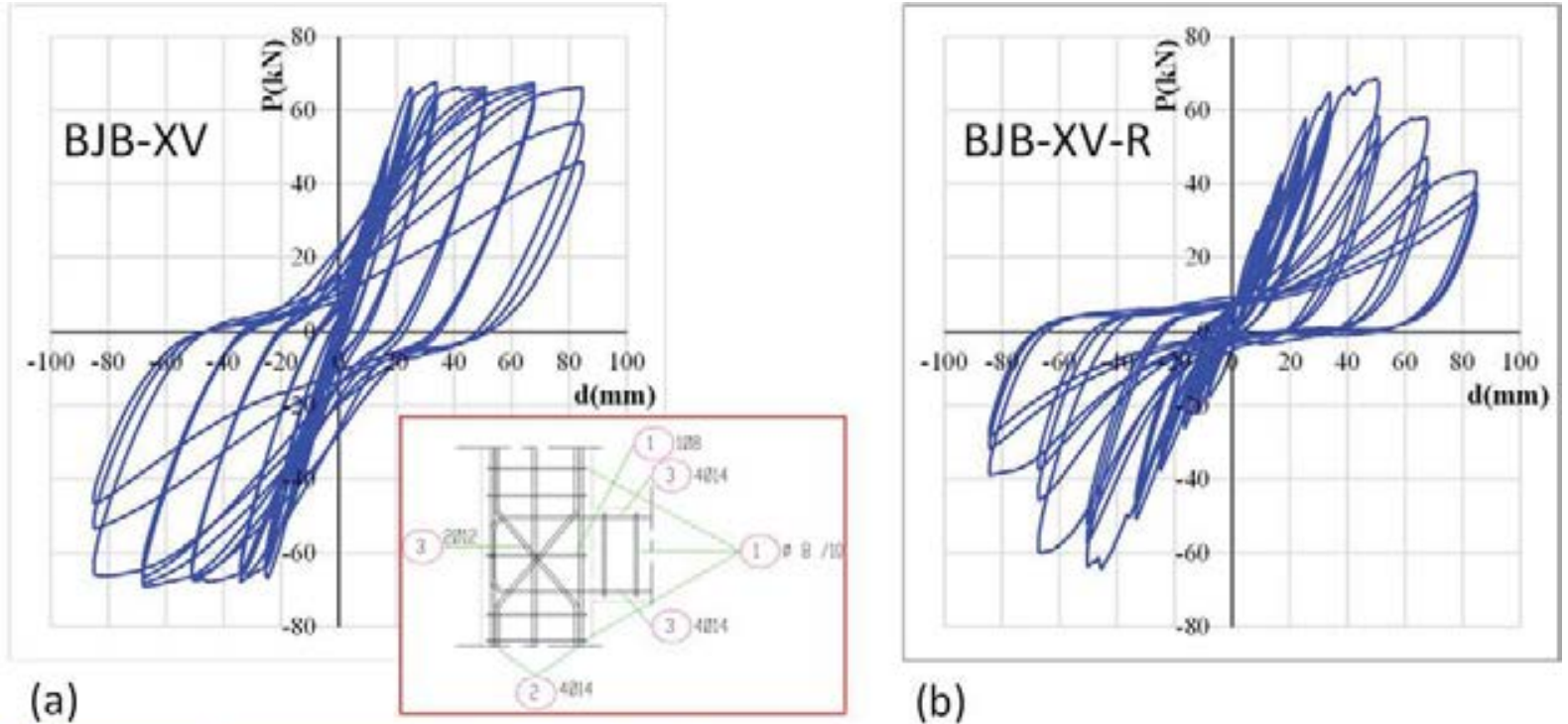

(a)

(b)

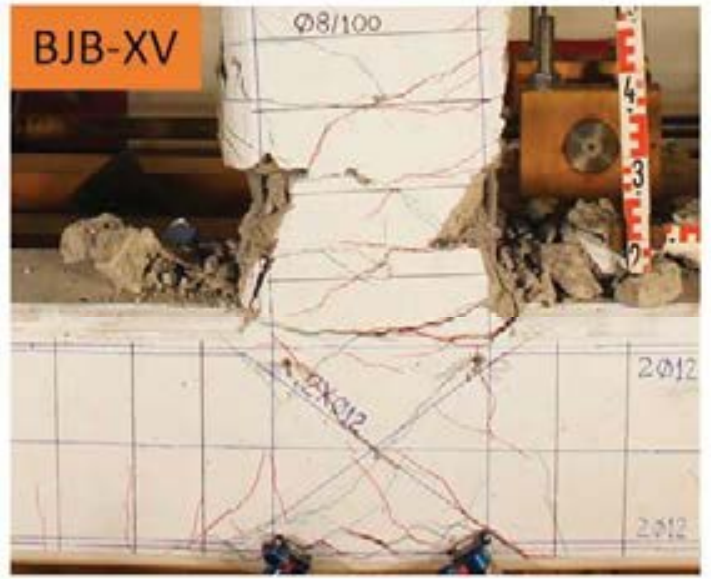

(c)

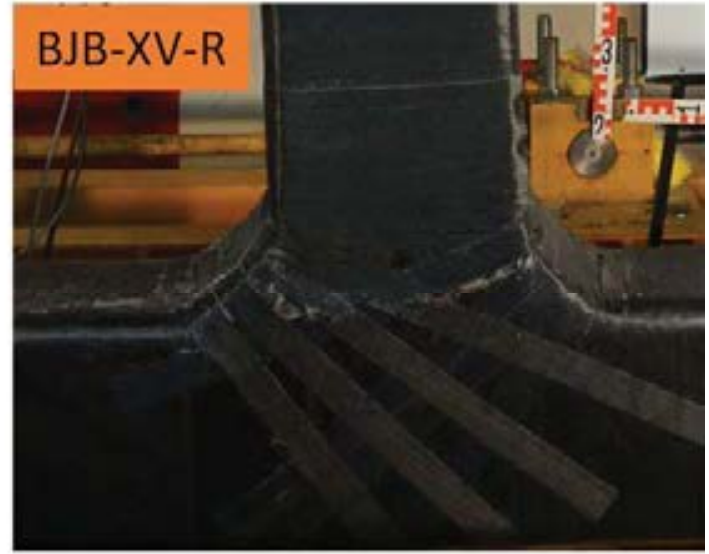

(d)

Figure 8: Hysteretic response (a) of the specimen BJB-XV and hysteretic response (b) of the corresponding repaired specimen BJB-XV-R and cracking pattern at the end of loading of the same specimens (c, d).

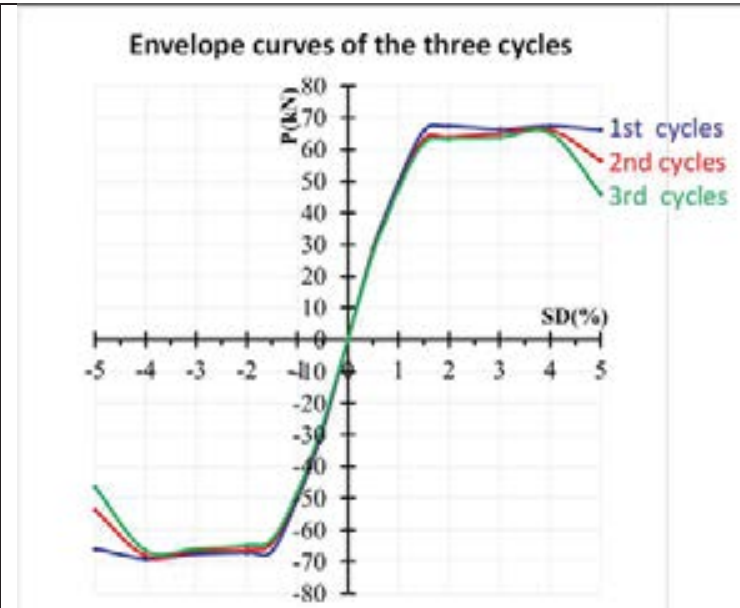

(a)

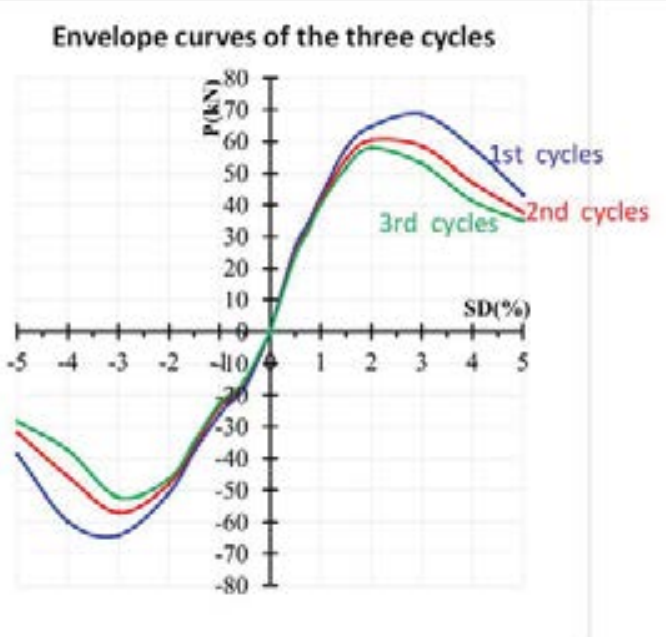

(b)

Figure 9: Envelop curves of the hysteretic responses (a) of the specimen BJB-XV and (b) of the corresponding repaired specimen BJB-XV-R. 


\subsection{Dissipated energy capacity}

A measurement for the assessment of the efficacy of the applied retrofitting technique can be the observed dissipated energy capacity in terms of the area of the hysteresis loops. Energy dissipation is an indication of the structural element capacity to be strained and it defines the energy that can be absorbed before the loss of the system stability.

The dissipated energy at 1st, 2nd and 3rd cycles of each loading step as measured in terms of the area of the corresponding hysteresis loops of the original specimen BJB-S1 are presented in Figure 10a. Further, the dissipated energy at 1st, 2nd and 3rd cycles of each loading step as measured in terms of the area of the corresponding hysteresis loops of the retrofitted specimen BJB-S1-R are presented in Figure 10b. Comparing the diagrams of retrofitted specimen with the corresponding diagrams of the original specimen it is deduced that the applied technique can rather adequately restore the energy dissipating capacity for the specimen designed according to earlier codes without the proper shear reinforcement in the joint body (only one stirrup in the joint area).

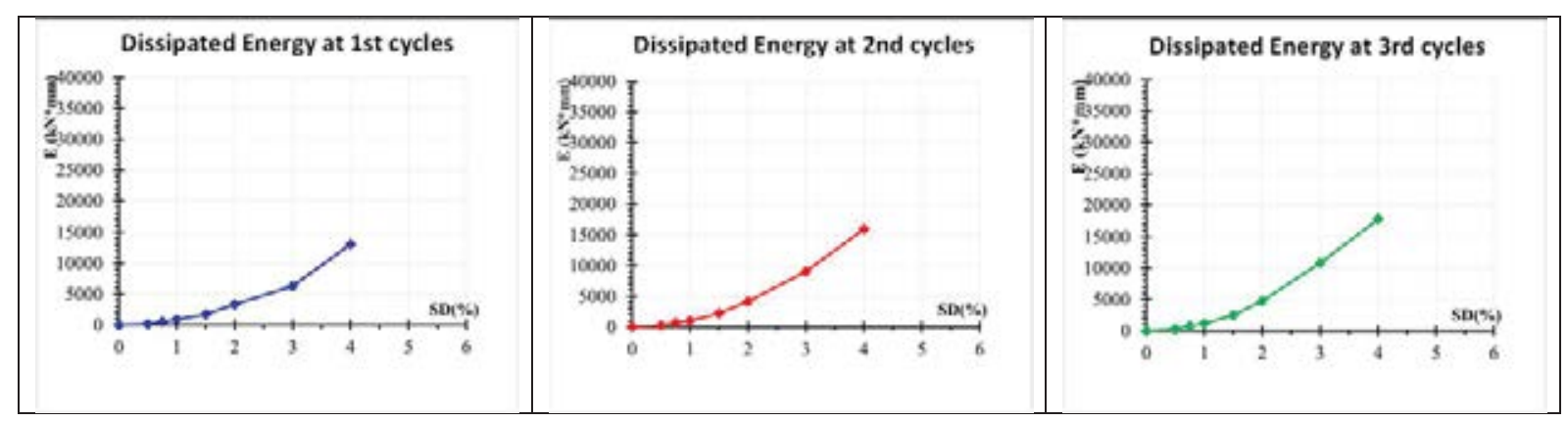

(a) Dissipated energy - Specimen BJB-S1

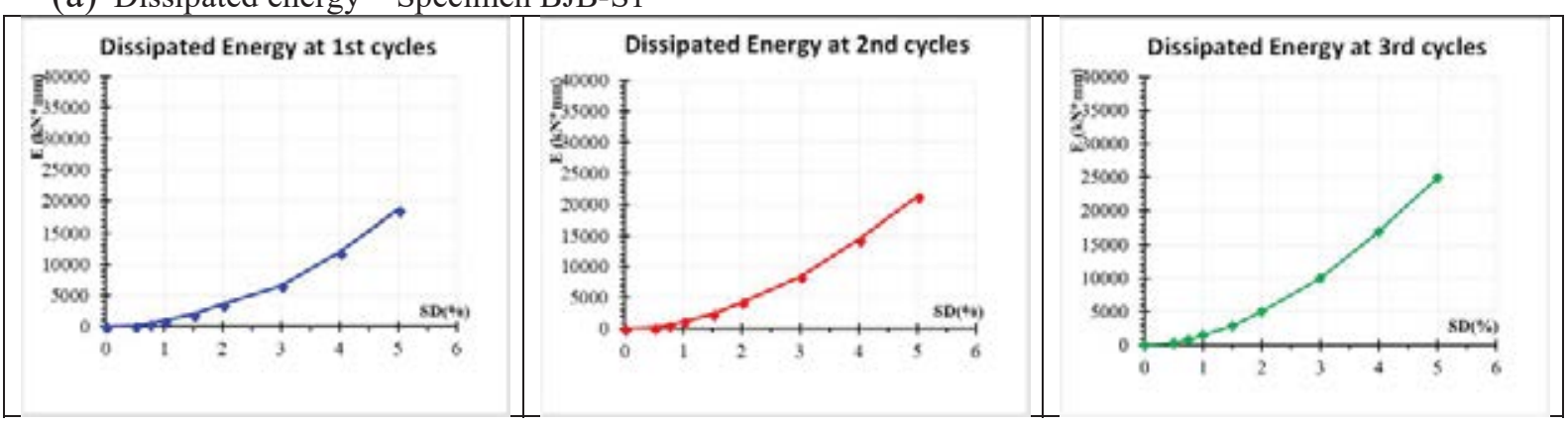

(b) Dissipated energy - Specimen BJB-S1-R

Figure 10: Energy dissipation per each loading step (a) of the specimen BJB-S1 and (b) of the corresponding retrofitted specimen BJB-S1-R.

The dissipated energy at 1st, 2nd and 3rd cycles of each loading step as measured in terms of the area of the corresponding hysteresis loops of the original specimen BJB-XV are presented in Figure 11a. Further, the dissipated energy at 1st, 2nd and 3rd cycles of each loading step as measured in terms of the area of the corresponding hysteresis loops of the retrofitted specimen BJB-XV-R are presented in Figure 11b. Comparing the diagrams of retrofitted specimen with the corresponding diagrams of the original specimen it is deduced that the applied technique can rather adequately restore the energy dissipating capacity for the specimen with X-type reinforcement in the joint (without stirrups).

However, from Figures 9 and 10 it can be observed that there are reservations about the efficiency of the technique in the restoration of the energy dissipation capacity in high levels of loading or high degree of initial damage. 


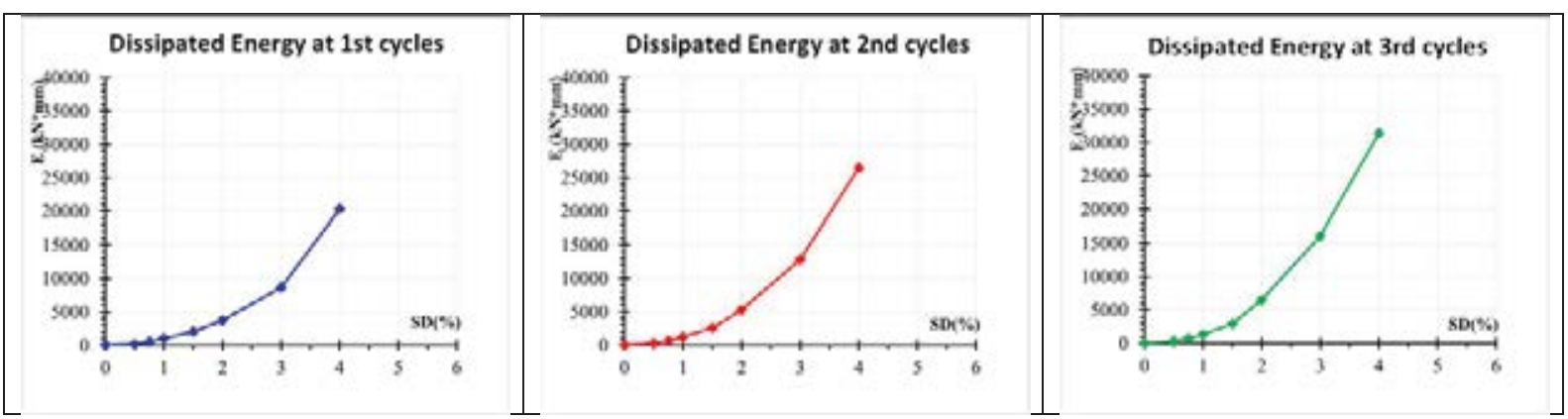

(a) Dissipated energy - Specimen BJB-XV

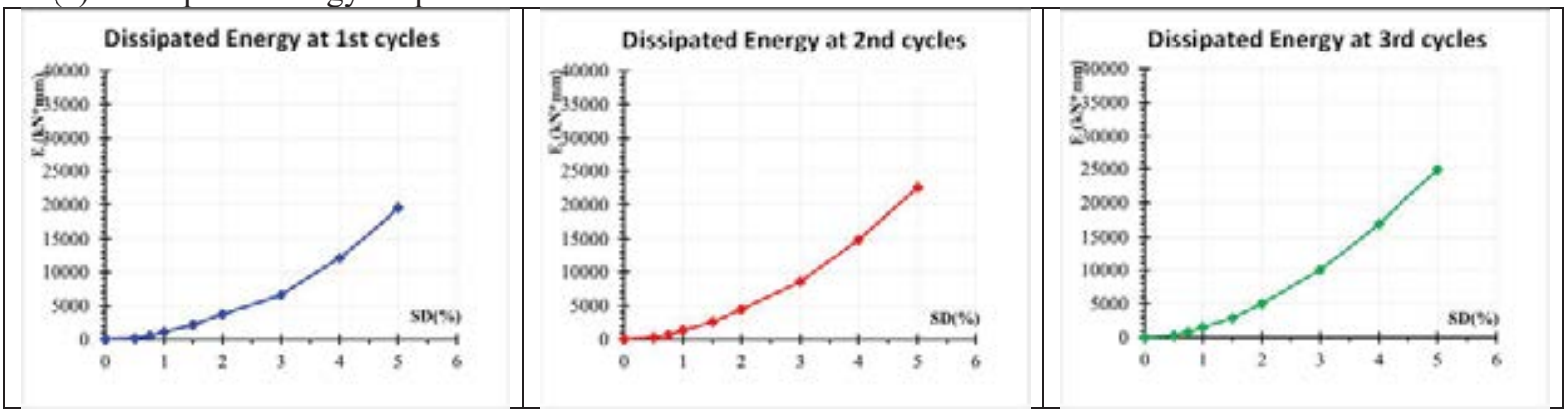

(b) Dissipated energy - Specimen BJB-XV-R

Figure 11: Energy dissipation per each loading step (a) of the specimen BJB-XV and (b) of the corresponding retrofitted specimen BJB-XV-R.

\section{CONCLUSIONS}

The efficacy of using C-FRP sheets for the retrofitting of damaged external beam column joints after seismic excitations is experimental studied. In the repair technique under investigation in this work, the C-FRP sheets are applied after a meticulous filling of the developing cavities and cracks but without the infusion of thin resin into the cracking system of the damaged area.

From the comparisons of the hysteretic responses of the original specimens with the hysteretic responses of the retrofitted ones it is deduced that in both cases the load bearing capacity values of all the retrofitted joints were almost equal to the ones of the original specimens in every loading step of the loading history.

Further, from the comparisons of the dissipated energy at 1st, 2nd and 3rd cycles of each loading step of the original specimens with the dissipated energy at 1st, 2nd and 3rd cycles of each loading step of the corresponding retrofitted ones it is deduced that the applied technique has rather adequately restored the energy dissipating capacity in the examined cases.

Finally, there are reservations for the efficiency of the technique in the restoration of the load bearing capacity and energy dissipation in cases of high level of loading or high degree of initial damage.

\section{REFERENCES}

[1] C.G. Karayannis, C.E. Chalioris, K.K. Sideris, Effectiveness of RC beam-column connection repair using epoxy resin injections. J. of Earthquake Engineering, 2(2), 217-240, 1998. 
[2] A.G. Tsonos, G.I. Kalogeropoulos, P.E. Iakovidis, D. Konstantinidis, Seismic retrofitting of pre-1970 RC bridge columns using innovative jackets., Int.J. of Structural Engineering, 8(2), 133-147, 2017.

[3] A.G. Tsonos, Effectiveness of CFRP-jackets in post-earthquake and pre-earthquake retrofitting of beam-column subassemblages. Structural Engineering and Mechanics, 27(4), 393-408, 2007.

[4] C.G. Karayannis, G.M. Sirkelis, Strengthening and rehabilitation of RC beam-column joints using carbon-FRP jacketing and epoxy resin injection. Earthquake Engineering and Structural Dynamics, 37, 769-790, 2008.

[5] A.G. Tsonos, Effectiveness of CFRP-jackets and RC-jackets in post-earthquake and preearthquake retrofitting of beam-column sub assemblages. Engineering Structures, 30(3), 777-793, 2008.

[6] D.J. Kakaletsis, K.N. David, C.G. Karayannis, Effectiveness of some conventional seismic retrofitting techniques for bare and infilled R/C frames. Structural Engineering and Mechanics, 39(4), 499-520, 2011. https://doi10.12989/sem.2011.39.4.499

[7] C. Marthong, Rehabilitation and strengthening of exterior RC beam-column connections using epoxy resin injection and FRP sheet wrapping: Experimental study. Structural En$\begin{array}{llll}\text { gineering and } & \text { Mechanices, 72019. }\end{array}$ https://doi.org/10.12989/sem.2019.72.6.723

[8] C.G. Karayannis, E. Golias, Full scale tests of RC Joints with minor to moderate damage repaired using C-FRP sheets. Earthquakes and Structures, 15(6), 617-627, 2018. https://doi:10.12989/eas.2018.15.6.617

[9] C.G. Karayannis, (2015), Mechanics of external RC beam-column joints with rectangular spiral shear reinforcement: experimental verification. Meccanica, 50(2), 311-322, 2015. https://doi:10.1007/s11012-014-9953-6

[10] C.G. Karayannis, B.A. Izzuddin, A.S. Elnashai, Application of adaptive analysis to reinforced concrete frames. J. Structural Engineering, ASCE, 120(10), 2935-2957, 1994. https://doi:10.1061/(ASCE)07339445(1994)120:10(2935)

[11] E. Golias, H. Lindenthal, F.-H. Schlüter, A.I. Karabinis, Ertüchtigung seismisch beschädigter Rahmenknoten aus Stahlbeton mittels FRP-Filamentbündelverbindungen. Bautechnik, 97(4), 268-278, 2020. https://doi.org/10.1002/bate.201900085

[12] C.E. Chalioris, A.G. Zapris, C.G. Karayannis, U-jacketing applications of fiber-reinforced polymers in reinforced concrete T-beams against shear - Tests and design, Fibers, 8(2), 13, 2020. https://doi.org/10.3390/fib8020013

[13] G.I. Kalogeropoulos, A.D. Tsonos, Cyclic performance of RC columns with inadequate lap splices strengthened with CFRP jackets, Fibers, 8(6), 39, 2020. https://doi.org/10.3390/fib8060039 